\title{
História Oral e as Ciências Humanas
}

\author{
Professor Doutor Edson Teixeira da Silva Júnior (Ciências Humanas - UniFOA) \\ - edsonuff@ig.com.br
}

\section{Resumo}

O presente artigo, "História Oral e as Ciências Humanas”, tem três eixos temáticos: o estudo da história oral relacionada aos debates da historiografia; a apresentação de uma metodologia básica para o uso de entrevistas em pesquisas científicas e o estímulo à iniciação de discentes, de cursos de graduação, que ao desenvolverem pesquisas com prazos reduzidos, possam utilizar fontes orais de forma criteriosa. No geral, apresentamos noções básicas que necessitam de um aprofundamento do tema.

Palavras-chave: 1. história oral; 2. ciências humanas; 3. entrevistas; 4. historiografia; 5. metodologia.

\begin{abstract}
:
This article, "Oral History and Human Science”, has three thematic axis: the oral history study related to historiography arguments, the presentation of basic methodology used in interviews in scientific research, and incentive students introduction in graduation courses, which developing researches in short time, will enable the use oral source in discerning form. In summary, this article shows-up basic notions that need to deepen the topic.
\end{abstract}

Key words; 1) Oral History; 2) Human Science; 3) interview; 4) historiography; 5) methodology

\section{História Oral e as Ciências Humanas}

O presente artigo tem como propósito verificar o uso da história oral e sua contribuição às ciências humanas, destacando sua contribuição na pesquisa acadêmica.

De início, apresentaremos um debate historiográfico sobre a história oral, procurando discorrer sobre seu conceito, sua validade e sua correlação com a historiografia. Com destaque para o grupo dos Annales, que reúne gerações de historiadores que reformularam muitos conceitos e metodologias na história, permitindo ao uso de fonte oral 
uma maior inserção na pesquisa. Em seguida, verificaremos a relação entre a história oral e a micro-história.

Correlacionaremos a importância da memória como fator individual e coletivo e sua importância para uma entrevista. Somado a isso, o papel crítico, e não meramente subjetivo, do pesquisador no trato com fontes orais.

Elaboramos uma síntese metodológica relacionada à história oral sem a pretensão de esgotar suas possibilidades. A literatura é rica no assunto e cabe aos pesquisadores solidificarem seu conhecimento sobre o tema. Algumas recomendações destacadas são essenciais para o bom uso da história oral, evitando os abusos que comprometam sua cientificidade. Trataremos da necessidade de um projeto científico para a história oral, os tipos de entrevistas, a importância da transcrição e os procedimentos mais comuns e recomendáveis para a realização de uma entrevista. Serão expostos os tipos de entrevista mais recomendados, como forma de auxiliar na escolha das fontes.

Por último, de modo didático, indicamos algumas sumárias sugestões para os trabalhos científicos de curto prazo dos discentes das ciências humanas. Estes, ao utilizarem as fontes orais, ou áudio-visuais, possam dispor de uma ferramenta conceitual e metodológica que não seja falaciosa e que propicie maior qualidade no esforço da sua atividade acadêmica. Ressalvamos que a história oral se insere num fértil debate historiográfico, sendo eficaz uma ampliação do seu conhecimento e de sua proposta. Por ser uma prática tão comum nas pesquisas acadêmicas que trabalham com períodos recentes, tem ganhado destaque e relevância, não apenas no Brasil, mas em outros centros internacionais de pesquisa. Se o presente artigo servir como estímulo para o aprofundamento do tema já extrapolou sua intenção inicial.

As fontes utilizadas no artigo foram concentradas na bibliografia especializada sobre o tema da história oral, sendo necessário compreender que, por ser uma atividade dinâmica, novas abordagens e novas metodologias podem aparecer, reforçando a tese de que trabalhar com fontes orais, além de prazeroso, exige constante atualização.

\section{A HISTÓRIA ORAL E A HISTORIOGRAFIA}

Em princípio, o pesquisador das ciências humanas pode compreender o termo história oral como uma tarefa específica dos historiadores. Tal situação pode ser explicada pela denominação história, seguida do termo oral. Entretanto, a história não é uma ciência monotemática. É imperativo, para a tarefa do historiador, estar em sintonia com as demais ciências humanas: a história é uma ciência multidisciplinar por excelência. Na história as metodologias empregadas reivindicam aprender e apreender com as outras metodologias científicas. É válido o caminho inverso. Nesse sentido, a história oral não é privilégio dos historiadores. 
Há um outro aspecto que precisa ser enumerado: nas últimas décadas assistimos a um complexo desenvolvimento no sistema de comunicação, disseminando o uso de aparelhos eletrônicos de gravação e filmagem, incidindo sobre a produção de pesquisas e requerendo adaptações. É um recurso vantajoso, aos alunos de graduação, pós-graduação, professores, enfim, pesquisadores. Ressalvando que na Grécia Antiga Tucídedes e Heródoto utilizaram fontes orais em suas pesquisas, o que demonstra que é o pesquisador que determina a originalidade de suas fontes e de seus procedimentos de pesquisa.

Mas o que vem a ser História Oral? Segundo Verena Alberti (2004):

“(...) a história oral é um método de pesquisa (histórica, antropológica, sociológica etc.) que privilegia a realização de entrevistas com pessoas que participaram de, ou testemunharam, acontecimentos, conjunturas, visões de mundo, como forma de se aproximar do objeto de estudo”.

Por que a história oral é uma metodologia de pesquisa? A resposta implica reconstruir o papel que essa metodologia teve na historiografia, ou seja, a escrita da história.

No século XIX, predominou na história, e nas ciências humanas, uma matriz teórica positivista que propiciou uma “quase ‘sacralização' do documento escrito, a prática de colher depoimentos esteve relegada a segundo plano” (ALBERTI, 2004). Com o positivismo, predominou a correlação dos fatos com a fonte documental. A abordagem centrada no indivíduo foi deslocada para segundo plano. Havia suspeitas sobre o depoimento oral. Este era visto como "uma visão parcial sobre o passado e estava sujeito a falhas de memória” (ALBERTI, 2004). Predominou a credibilidade dos documentos escritos, supostamente dotados de uma precisão e neutralidade.

No entanto, para o pesquisador, antes de se tornar um documento, o registro escrito é elaborado por alguém com uma determinada carga de subjetividade, uma determinada “visão de mundo”, uma determinada ideologia. Cabe ao pesquisador tornar aquele registro escrito um documento para sua pesquisa, procurando reter, criticamente, quais os elementos que ele traduz em sua devida época. Um exemplo hipotético: o diário de um dos maiores líderes políticos do país, Getúlio Vargas. A rigor, este é um registro pessoal de um protagonista político e ,devido a esse protagonismo, seus registros tornam-se indispensáveis para a análise histórica. Um outro diário, de um cidadão qualquer, não protagonista, que tenha desempenhado a função de dirigente sindical no período no qual Getúlio Vargas foi presidente, também é um registro. Ambos tornam-se documentos a partir das análises que os pesquisadores priorizarem num projeto de pesquisa. Nos dois casos está presente a subjetividade, seja a do estadista, seja a do sindicalista. Isso não bastava aos críticos da história oral.

A historiografia do século XX foi aos poucos revendo os conceitos teóricos do século XIX: 
"Especialmente ao longo dos anos 60 e 70, predominou na historiografia a tendência de valorizar as análises das estruturas, os processos de longa duração, e, em contrapartida, de desvalorizar os estudos sobre a conjuntura política ou cultural, o fato histórico singular e seu protagonista individual. Nesse movimento, o uso das fontes seriais e de técnicas de quantificação assumiu importância fundamental, enquanto o recurso a relatos pessoais, história de vida, biografias passou a ser visto como extremamente problemático" (AMADO, 1996, p. xxii, Introd.).

Se não bastasse a validade do documento escrito, a história oral foi preterida pela utilização de métodos de pesquisa que tinham sua base documental quantitativa, estabelecendo longos períodos de pesquisa, com ênfase na histórica econômica. Após a Segunda Guerra Mundial (1939-1945), houve um questionamento do método quantitativo e um interesse pelo método qualitativo. As abordagens sobre metodologias quantitativas e qualitativas não se anulavam, contribuindo para a utilização da história oral:

"A virada dos anos 70 para os anos 80 trouxe transformações expressivas nos diferentes campos de pesquisa histórica, revalorizando a análise qualitativa, resgatando a importância das experiências individuais, promovendo um renascimento do estudo político e dando impulso a história cultural. Nesse novo cenário, os depoimentos, os relatos pessoais e a biografia também foram revalorizados, e muitos dos seus defeitos, relativizados. Argumentou-se, em defesa da abordagem biográfica, que o relato pessoal pode assegurar a transmissão de uma experiência coletiva e constituir-se numa representação que espelha visão de mundo" (AMADO, 1996, p. XXII, Introd.).

Sofreu alteração o preconceito contra as fontes orais. Dito de outra forma:

"para alguns historiadores tradicionais os depoimentos orais são tidos como fontes subjetivas por nutrirem-se da memória individual, que às vezes pode ser falível e fantasiosa. No entanto, a subjetividade é um dado real em todas as fontes históricas, sejam elas orais, escritas ou visuais” (FREITAS In THOMPSON, 1992, p. 18, Introd.).

Ou ainda: "a história oral é legitima como fonte porque não induz a mais erros do que outras fontes documentais e históricas. O conteúdo de uma correspondência não é menos sujeito a distorções factuais do que uma entrevista gravada” (CAMARGO In ALBERTI, 2004, p. 13).

A receptividade da história oral se insere no amplo debate que se estabeleceu na França, com a criação da revista Annales, em 1929. A revista teve como marca primordial a inovação historiográfica, não confundindo com o modismo historiográfico, tão mal 
aplicado por alguns pretensos pesquisadores, atualmente. Nessa revista, despontaram os nomes de Lucien Febvre, Marc Bloch, Fernand Braudel, Georges Duby, Jacques Le Goff, entre outros. Vários grupos e gerações de pesquisadores que questionaram a escrita da história. A primeira fase, compreendida entre 1920 a 1945, caracterizou a história como problema e não como simples narrativa de fatos e acontecimentos; refutou a história política e conduziu as atenções para outras atividades humanas; além disso, foi essa geração que, meritamente, seduziu os historiadores a buscarem o diálogo científico com as outras ciências.

A segunda fase vai do pós Segunda Guerra Mundial até meados da década de 60, mais exatamente 1968. Consolidou a pesquisa no estudo das estruturas, em longa duração, privilegiando o método quantitativo. A terceira fase, pós-68 - período de grandes mudanças e questionamentos no mundo, mas também de muitas ditaduras insanas - reconduziu o indivíduo para o centro das abordagens históricas: biografias, história política, histórica cultural direcionaram as atenções dos historiadores, junto a isso o método qualitativo ganhava força e com ele a história oral.

Mesmo assim as dúvidas em relação à história oral permaneciam. Como exemplo: como confiar num depoimento após um fato histórico consumado? O discurso sempre traz uma memória seletiva. Foi necessário fundamentar a relação entre história e memória para melhor explicar a validade da história oral e das novas teorias surgidas na historiografia.

O termo memória nos remete a análise de Michael Pollak (1992), para quem "a memória parece ser um fenômeno individual, algo relativamente íntimo, próprio da pessoa”. Mas, a impressão inicial se amplia, pois a "a memória deve ser entendida como um fenômeno construído coletivamente e submetido a flutuações, transformações, mudanças constantes”. Segundo o mesmo autor, a memória é constituída por três critérios: acontecimentos, personagens e lugares. Os acontecimentos podem, em primeira instância, ser "vividos pessoalmente", posteriormente, com nova dinâmica passam a ser "acontecimentos vividos pelo grupo ou pela coletividade à qual a pessoa se sente pertencer”. Há casos onde memória é projetada para um acontecimento que não foi vivido pela pessoa, uma projeção da memória, conforme explica Pollak: “é perfeitamente possível que, por meio da socialização política, ou da socialização histórica, ocorra um fenômeno de projeção ou identificação com determinado passado”. Outro elemento constitutivo da memória são as pessoas, personagens, que no mesmo sentido dos acontecimentos podem ter compartilhado o contato direto com quem recorda, ou que também podem ser projetados em função da socialização e da relevância de uma personagem para determinado período e grupo social. A definição de lugares pode estar relacionada a monumentos que indicam algum marco da vida da pessoa ou marcos históricos, ou também "lugares particularmente ligados a uma lembrança, que pode ser uma lembrança pessoal, mas também pode não ter o apoio no tempo cronológico". A memória é um fenômeno que contribui para formar a identidade de um indivíduo. 
Há íntima relação entre a história oral e a memória. Nesse sentido, a tarefa do pesquisador é fundamental. Aliás, "as duas partes (entrevistado e entrevistadores) constroem, num momento sincrônico de suas vidas, uma abordagem sobre o passado, condicionada pela relação da entrevista, que se estabelece em função das peculiaridades de cada uma delas” (ALBERTI, 2004, p.23).

Cabe ao entrevistador desempenhar uma análise crítica do depoimento, tendo como base a compreensão que o discurso realizado no presente, embora se remeta ao passado, congrega a memória de um indivíduo num contexto social que não deve ser desprezado. E essa memória não é isolada de um indivíduo inserido numa coletividade; a memória reproduz o que nem sempre os registros da história oficial disponibilizam. É indispensável questionar se a objetividade não estaria comprometida no ato da entrevista. Isso exige do entrevistador a ética, a responsabilidade, a competência e a honestidade com a produção científica.

A história oral também se relaciona com a oportunidade de propiciar, ao conjunto dos setores sociais, uma versão dos fatos oposta as fontes oficiais. No debate historiográfico, na década de 60, houve a inserção da micro-história, em oposição à macro-história, ao discurso hegemônico na sociedade e uma oportunidade para dar vez e voz aos demais atores sociais. Conforme foi advertido: "nenhum sistema normativo é suficientemente estruturado para eliminar qualquer possibilidade de escolha consciente, de manipulação ou de interpretação das regras, de negociação” (LEVI, In AMADO, 2002, p. 179). Nesse sentido, a história oral constitui-se em uma metodologia - não a única - eficaz para a microhistória, permitindo a construção de um discurso e as múltiplas possibilidades de "escolhas e decisões” do indivíduo diante do sistema normativo que está inserido.

\section{ALGUMAS OBSERVAÇÕES SOBRE A METODOLOGIA DA HISTÓRIA ORAL}

Passaremos a enumerar algumas normas que são basilares da entrevista em história oral. Entretanto, é necessário advertir que o que for aqui exposto não é o suficiente para o uso dessa metodologia, é recomendável uma pesquisa mais apurada sobre a literatura que trata do tema.

Em primeiro, é necessária uma advertência: “fazer história oral não é simplesmente sair com um gravador em punho, algumas perguntas na cabeça, e entrevistar aqueles que cruzam nosso caminho dispostos a falar um pouco sobre suas vidas” (ALBERTI, 2004, p.29). Antes da possibilidade da entrevista, deve-se elaborar um projeto de pesquisa. Este exige um domínio sobre o tema a ser desenvolvido, sua historicidade e um levantamento bibliográfico abrangente. Além disso, é necessário verificar a relevância do tema no contexto em que é produzido. A pesquisa começa a ganhar contornos originais com o estabelecimento dos objetivos e das hipóteses a serem verificadas. Os conceitos que fundamentam a pesquisa merecem destaques à parte, assim como a metodologia a ser 
empregada. É necessário definir as fontes a serem pesquisadas, definindo as fontes primárias e secundárias. A viabilidade de um projeto de pesquisa está condicionada ao tipo de fontes e ao tratamento que a elas será dado. As fontes secundárias reúnem livros, monografias, dissertações e teses que tratam do tema. As fontes primárias são amplas, são os registros que se tornam documentos a partir dos critérios adotados pelo pesquisador, podem ser encontradas em jornais, revistas, cartas, documentos oficiais, entre outros. As fontes disponibilizadas em sítios da “internet” podem ser usadas, mas com cautela e com credibilidade. Não é recomendável um mecanicismo de recortar e colar informações de sítios desprovidos de credibilidade acadêmica. Na mesma direção podemos destacar o uso do correio eletrônico. Há pesquisadores que desenvolvem sua atividade através desse recurso. No geral, o correio eletrônico tem o inconveniente de ser parte de um relato em que entrevistado e entrevistador estão distantes. Deve-se ser usado para sanar dúvidas, não deve ser o conteúdo principal de um depoimento.

Dentro de uma pesquisa, é importante delimitar o tema cronologicamente, lembrando que não é obrigatório trabalhar a cronologia de modo contínuo. Por fim, é imperativa a existência de um cronograma provisório, demarcando a execução do projeto.

A inserção da história oral num projeto requer algumas peculiaridades. Uma exigência é relacionada ao marco cronológico estabelecido: a história oral "só pode ser empregada em pesquisas sobre temas recentes, que a memória dos entrevistados alcance. (...) a realização de entrevistas pressupõe o estudo de acontecimentos e/ou conjunturas ocorridos num espaço de aproximadamente 50 anos” (ALBERTI, 2004, p.21).

Logo, não se deve fazer história oral de baixo nível. Muitos alunos de graduação acumulam vícios do ensino fundamental e médio, são raras as escolas que ensinam a pesquisar. Há uma cultura da cópia sem análise crítica, sem problematização, sem qualquer critério. Muitos educadores são despreparados para exigir dos seus alunos um rigor científico, sem esquecer que a carga horária desses educadores é ultrajante, assim como a absurda remuneração a que estão submetidos.

Um exemplo da cultura que se forma no ensino é a inaptidão para a análise de gráficos e dados estatísticos. Alguns docentes e discentes cometem a falácia de usar esses recursos como mero elemento decorativo numa pesquisa. Um gráfico e os dados estatísticos se não forem problematizados, se não forem traduzidos dentro dos critérios préestabelecidos numa pesquisa, passam a ser caso único de charlatanismo científico.

Resumidamente, o uso da história oral exige a prévia elaboração de um projeto de pesquisa, de um manuseio criterioso do conhecimento científico. Além disso, as fontes orais a serem trabalhadas devem ser recentes, adequadas ao tema, e dotadas de credibilidade.

Existem dois tipos básicos de entrevistas e, consequentemente, de entrevistados na história oral: a entrevista temática e a entrevista de história de vida. É preciso advertir que não basta ter um número razoável de pessoas a serem entrevistadas, é preciso aplicar o método qualitativo na natureza de cada depoimento. Segundo Alberti (2004): “convém 
selecionar os entrevistados entre aqueles que participaram, viveram, presenciaram ou se inteiraram de ocorrências ou situações ligadas ao tema e que possam fornecer depoimentos significativos”. Portanto, na elaboração do projeto de pesquisa é indispensável a proposição de critérios na escolha dos entrevistados, listando as possíveis fontes orais a serem colhidas. Em seguida, com as informações já reunidas, ou seja, com um conhecimento ampliado do tema a ser pesquisado e os pressupostos científicos definidos, passamos a uma nova fase que tem como cerne o perfil do entrevistado e o tipo de entrevista que será realizada. Qual a relação entre entrevista temática e a entrevista de história de vida?

“(...) as entrevistas temáticas são aquelas quem versam prioritariamente sobre a participação do entrevistado no tema escolhido, enquanto as de história de vida têm como centro de interesse o próprio indivíduo na história, incluindo sua trajetória desde a infância até o momento em que fala, passando pelos diversos acontecimentos e conjunturas que presenciou, vivenciou ou de que se inteirou. Pode-se dizer que a entrevista de história de vida contém, sem seu interior, diversas entrevistas temáticas” (ALBERTI, 2004, p.37).

Esses dois tipos de entrevistas estão associados às circunstâncias em que será realizado o depoimento. Uma fonte oral cuja história de vida seja fundamental devido a seu protagonismo, ou função social desempenhada, talvez possa se converter numa fonte temática. Tal razão é estabelecida pelo tempo e período que o entrevistado dispõe para fornecer o depoimento. Nem sempre as pessoas estão dispostas a fornecer dados pessoais da sua biografia. A rigor, é comum todo cuidado na listagem das possíveis fontes orais, pois é nesse momento que se delimita o tipo de entrevista a ser realizado, lembrando que a flexibilidade pode ser um fator favorável ao trabalho de pesquisa, nunca um estorvo.

Uma observação pertinente: entendemos fonte oral como “o material recolhido por um historiador para as necessidades de sua pesquisa, em função de suas hipóteses e do tipo de informações que lhe pareça necessário possuir” (VOLDMAN In AMADO, 2002, p.36). Compreendemos que a mesma definição tem validade aos demais pesquisadores das ciências humanas e que não há diferença entre a definição de história oral e fonte oral. Ambas são complementares: a fonte oral é a matéria-prima básica da concretização da historia oral, associada a um projeto de pesquisa. No ramo científico da história, a denominação história oral está ligada aos programas que reúnem arquivos a partir de fontes orais. Há trabalhos de pesquisa individuais que utilizam à fonte oral sem os requisitos de um programa de história oral, nem por isso quem utiliza fonte oral pode desprezar as regras mínimas inerentes à história oral.

Definidas as entrevistas a serem desenvolvidas, o passo seguinte é elaborar um roteiro da entrevista. O roteiro funciona como um guia da entrevista, uma forma de definir os caminhos da entrevista. De acordo com Paul Thompson (1992): 
"Normalmente é muito melhor saber as perguntas, fazê-las diretamente no momento oportuno, e manter o roteiro em segundo plano. Ele é essencialmente um mapa para o entrevistador; pode-se recorrer a ele ocasionalmente, mas o melhor é tê-lo na cabeça, de modo que se possa percorrer o território com segurança”.

Podem ocorrer situações não previstas no roteiro. Nesse caso, cabe ao pesquisador ter a habilidade suficiente e a perspicácia de introduzir uma pergunta que possa esclarecer a declaração do depoente. Tal situação pode ocorrer à medida que o entrevistado fornecer dados relevantes, desconhecidos dos entrevistadores. Entretanto, todo depoimento tem a obrigação - como qualquer documento - de ter verificada a autenticidade e veracidade dos fatos narrados. No caso de um episódio narrado, com conteúdo inédito, o mais aconselhável é correlacionar esse episódio com documentos escritos ou outras fontes orais relacionadas ao tema estudado.

No ato da entrevista, deve-se levar em consideração o esforço que o entrevistado desempenha na reconstrução do passado. Nesse sentido, não é aconselhável interrupções. O mais conveniente é compreender que o entrevistado dita o ritmo, o entrevistador o delimita, sem mudar bruscamente o curso da conversa. Para isso, o roteiro é fundamental e indispensável. Thompsom (1992) faz uma observação pertinente sobre a elaboração das perguntas:

“As perguntas devem ser sempre tão simples e diretas quanto possível, em linguagem comum. Nunca faça perguntas complexas e de duplo sentido - em geral, apenas uma de suas metades será respondida e, em geral, não ficará claro qual delas. As perguntas pessoais delicadas devem ser feitas de maneira cautelosa ou indireta, previamente elaborada e proposta de maneira que demonstre segurança”.

Um detalhe não pode passar despercebido pelo entrevistador: o cuidado com o equipamento que irá utilizar numa entrevista. O seu estado e a sua qualidade merecem atenção especial. A maneira como será utilizado na entrevista é primordial para estabelecer uma relação de confiança e evitar constrangimentos aos envolvidos. O mais comum seria as entrevistas serem realizadas por duas pessoas, sendo uma responsável pela sua condução e a outra responsável pela gravação, advertindo que a segunda pessoa pode intervir na entrevista, complementando algum trecho que julgue pertinente, ela não é um mero espectador. Tal medida visa garantir a execução da entrevista sem interrupções que possam interferir nas declarações do entrevistado. Os cuidados técnicos são medidas cautelares para não se perder todo o trabalho desenvolvido: imagine perder um depoimento por falta de pilha, fitas, ou algum componente danificado. Caso a entrevista seja realizada por um único entrevistador, este deve levar em conta as mesmas observações enumeradas e deter uma experiência sobre essa metodologia. 
Uma ferramenta de uso comum na sociedade são as câmeras contidas em aparelhos eletrônicos. Por dois fatores não é aconselhável utilizar uma entrevista com o recurso do áudio-visual: primeiro, a câmera pode inibir o entrevistado, comprometendo o objetivo da pesquisa. Segundo, o custo da reprodução é elevado, exigindo recursos que podem inviabilizar o desenvolvimento do projeto. Entretanto, com o tempo, com o uso comum das câmeras, essas observações podem se tornar obsoletas. Recomendamos que antes da entrevista seja comunicado ao entrevistado se há alguma objeção ao uso de câmeras; entretanto, é mais prudente realizar a entrevista gravada, em áudio.

O local da entrevista deve ser adequado e restrito. De preferência escolhido pelo entrevistado, oferecendo condições mínimas para a sua realização. De preferência, um local que o entrevistado possa dispor de documentos, como fotos, artigos de jornais, etc. Deve-se observar o conforto das partes envolvidas no ato da entrevista, permitindo o desenrolar da tarefa de modo menos desgastante. Outra medida de segurança é a verificação dos sons externos que possam interferir na captação do áudio, tomando providências para evitar ruídos comprometedores.

A etapa posterior implica reproduzir uma cópia da entrevista evitando imprevistos. Em concomitância são fundamentais algumas anotações antes ou logo após a entrevista, como o nome do entrevistado, a data, o local, cidade, o seu estado e o tempo de gravação. A fase posterior é de suma importância, trata-se da transcrição e edição do texto final. Nessa tarefa a melhor opção é a transcrição literal, incluindo as interjeições, os silêncios, as reações emotivas, que são elementos significativos da memória do entrevistado. Indispensável é o conhecimento das normas gramaticais atenuando as dúvidas:

"gramática e a ordem das palavras devem ser deixadas como foram faladas. Se não se conseguir compreender um palavra ou uma frase, deve deixar-se um espaço na transcrição para indicar isso. A verdadeira arte do transcritor está no uso da pontuação e numa ou outra grafia fonética que transmita a natureza da fala” (THOMPSON, 1992, p.293.) .

A duração de uma entrevista deve ter no máximo duas horas. Mais do que isso pode ser cansativo e imprudente. Caso haja disponibilidade do entrevistado, vale prorrogar, mas verificando a qualidade do discurso em sua totalidade.

O contato inicial entre entrevistado e entrevistador e o prévio estabelecimento das regras são fundamentais. Nesse momento é indispensável a confiança transmitida ao entrevistado, o esclarecimento de todas as etapas a serem empregadas, o esclarecimento que as entrevistas serão gravadas, transcritas e o entrevistado terá a oportunidade de revisá-las. E, de modo fundamental, apresentar algum documento que identifique o entrevistado e sua função profissional vinculada a alguma instituição, isso dá mais credibilidade. Informalmente, o entrevistado é comunicado que seu depoimento constará de uma pesquisa e ele autorizará o uso do seu conteúdo. Entretanto, só ao final da entrevista apresenta-se um 
termo de compromisso entre as partes envolvidas. Não se deve temer esse encaminhamento, corre-se o risco de inibição do entrevistado, além dele fugir a temáticas que possam ser elucidativas, ressaltando a lisura de todo o processo, como a revisão que lhe é assegurada antes da permissão do seu uso público.

Enumeramos, com base em Thompson (1992), algumas regras básicas da metodologia da história oral:

1. "Deve-se dar prioridade para entrevista com pessoas de certa idade. É preciso levar em conta o cansaço da testemunha, limitar o tempo das entrevistas e evitar perguntas, excessivamente, meticulosas do ponto de vista cronológico. Pode acontecer que, decepcionada por não poder responder, a testemunha se perturbe e abrevie a entrevista”. Isso não impede que pessoas de outras idades possam ser entrevistadas, as de mais idade, normalmente, possuem um discurso elaborado.

2. "O entrevistador deve, antes de mais nada, saber guardar silêncio, aprender a ouvir”. A interrupção do entrevistado é uma negligência científica. O silêncio do entrevistado pode ser uma pista importante para a construção da memória.

3. "Deve repetir as palavras do entrevistado, caso estas não forem claramente audíveis. Procurar não falar ao mesmo tempo em que a testemunha; não insistir quando evita uma recordação dolorosa”. Se algo não foi compreendido, o melhor é retomar ao tema nos próprios termos da declaração do entrevistado, solicitando-lhe que explique melhor um assunto, o que na prática significa não interromper e nem interferir no raciocínio do mesmo. Uma “recordação dolorosa” pode ser seguida de manifestações emotivas que requer um cuidado especial. Se for algo que deixe o entrevistado transtornado é aconselhável uma pausa, sugerindo o seu retorno, verificando se o entrevistado quer continuar a entrevista.

4. "A relação testemunha [entrevistado]-entrevistador às vezes prossegue depois da entrevista". A história oral envolve pessoas e seus sentimentos, terminar uma entrevista sem uma conversa informal é algo que põe em jogo a credibilidade de todo o trabalho. $\mathrm{O}$ entrevistado pode recordar algum assunto que não foi explorado, este deve ser anotado, e posteriormente, numa revisão ou nova entrevista, solicitar a sua explicação.

5. "O local mais indicado para a entrevista é a casa do entrevistado ou no local de trabalho”. Nesses locais há a possibilidade do entrevistado possuir documentos complementares ao seu depoimento. São locais de sua cotidianidade e lhe dão segurança numa proposta de entrevista que, posteriormente, será de uso público. Caso haja, além dos entrevistadores, uma pessoa acompanhando o entrevistado, o ideal é que esta não interrompa, caso insista em interromper cabe uma sugestão: um novo depoimento. No entanto, se essa mesma pessoa for útil no depoimento, que está sendo realizado, como no caso de um casal que vivenciou determinado acontecimento, nada impede a participação e o estímulo às opiniões do entrevistado. 
6. "Deve-se traçar um roteiro da entrevista; isso não significa que o entrevistador deva cumpri-lo à risca". Lembrando sempre que o roteiro é flexível; um guia para a entrevista, nunca uma camisa-de-força.

7. "Deve-se preparar um corpo central de perguntas, que no decorrer da entrevista podem ser utilizadas". Precavendo-se para não ser repetitivo e nem permitir ao entrevistado se esquivar de uma pergunta com um "sim" ou "não". A pergunta tem que oportunizar ao entrevistado uma declaração abrangente.

8. "A entrevista em si não é realizada de modo perguntas-respostas. O ideal é ir se adequando ao que a testemunha for lembrando, aos poucos faça com que ela se encaixe no seu roteiro e nas suas perguntas". Quem conduz a entrevista, em certa medida, é o entrevistado, daí não haver a necessidade de rigidez cronológica na sua exposição. Cabe ao pesquisador ter sensibilidade - quando perceber a divagação do entrevistado - e conduzi-lo ao raciocínio seqüencial que este estava expondo.

9. "Duas horas de entrevistas talvez seja uma boa medida". Tanto na entrevista temática quando na entrevista de história de vida esse é o tempo recomendável. Há casos em que serão realizadas várias seções de entrevista, o que serve para refazer o roteiro e as perguntas a serem encaminhadas.

10. "A transcrição deve ser feita o quanto antes”. Corre-se o risco de perder o conteúdo completo da entrevista e pode levantar dúvidas quanto à possibilidade de revisão do entrevistado.

11. "As passagens pouco audíveis podem ser colocadas em colchetes". Tal medida maximiza uma transcrição e viabiliza correções que possam qualificar o depoimento.

12. "As dúvidas, os silêncios, as rupturas sintáticas, assinaladas por reticências. O texto será organizado cuidadosamente por parágrafos, devendo-se atentar para a pontuação, que é imprescindível à boa compreensão do texto". Esta recomendação refere-se à fidelidade da transcrição e a necessidade do conhecimento gramatical na sua tarefa.

Evidentemente, que são muitas as recomendações para a realização da história oral e sua eficácia na tarefa de pesquisa. Mas, o essencial é ter um ponto de partida demarcado pela cientificidade de um projeto e o respeito às normas metodológicas enumeradas. 


\section{O USO DA HISTÓRIA ORAL PELAS CIÊNCIAS HUMANAS EM SITUAÇÕES IMEDIATAS}

Como abordado acima, a história oral é recomendada para programas de instituições que objetivem à montagem de um arquivo público e em atividades isoladas de pesquisas, não restritas aos historiadores, desempenhadas em programas de pesquisas específicos. Não há nenhuma restrição ao seu uso por um único pesquisador que elabore monografias, dissertações ou teses, desde que siga as regras gerais e faça uma adequação rigorosa. Uma diferença é que o trabalho de história oral, quando ligado a um programa, requer a montagem de uma equipe qualificada, incluindo operador de áudio e som, transcritores, editores especializados, permanentes equipamentos eletrônicos de qualidade incontestável e espaço físico condizente com as necessidades de armazenamento, transcrição, edição, produção e acesso ao arquivo ao público interessado. Há um potencial suficiente para o emprego de estagiários, que no caso de instituições de ensino superior, podem recorrer aos discentes de graduação e iniciação científica, aprimorando ainda mais seus conhecimentos.

Para historiadores e para pesquisadores das ciências humanas, uma atividade não pode ser desprezada: na elaboração de trabalhos ao longo de seus cursos de graduação, trabalhos específicos das mais variadas disciplinas, a contextualização dos temas abordados sugere a utilização de fonte oral como metodologia. É comum o emprego de entrevistas, filmagens e metodologias muito próximas da história oral, porém, carentes de um rigor científico. A diferença de um programa voltado para a construção de um arquivo, atividade comum na história oral, com esses trabalhos é que o pesquisador trabalhará com um número de fontes orais reduzido, o seu objeto de pesquisa é restrito e a fonte oral é um elemento que visa contribuir na pesquisa. Num programa de história oral, as fontes orais são elementos centrais do objeto da pesquisa.

No entanto, o corpo discente dispõe cada vez mais de ferramentas eletrônicas com potenciais diversos. Se não forem devidamente orientados, podem arruinar todo o potencial positivo que possuem. Seria ideal que as disciplinas que tratam da metodologia da pesquisa acadêmica reservassem um tópico especial do uso das fontes orais, introduzindo o discente na metodologia. O discente, além do estímulo e motivação, ganhará cientificidade na sua formação, auxiliando no combate aquela cultura da cópia sem problematização e critérios que já citamos.

É conveniente adequar às normas inerentes a história oral aos trabalhos que são sugeridos pelos docentes e que viabilizam o uso de fonte oral. Esses trabalhos possuem prazos relativamente curtos. Um problema é que nem sempre tais trabalhos estão inseridos num projeto de pesquisa e no rigor que todo projeto contempla. Isso não impede que docentes e discentes possam, a partir dos temas pesquisados, estabelecer os objetivos da pesquisa. Pré-condição irrefutável é o máximo conhecimento do tema. Se este permite o uso de entrevistas, convém aos envolvidos nas suas respectivas tarefas adequarem-se ao uso 
de fonte oral. O que recomendaremos não implica solução final das deficiências existentes no ensino universitário, mas apenas um auxílio metodológico.

Se o autor de uma pesquisa, de dimensões curtas, tiver um tema a ser desenvolvido que se relacione ao tempo presente, ou seja, que viabilize a utilização de fontes orais, não há nenhum empecilho. A primeira recomendação é não usar a fonte oral como mero elemento decorativo. Se ao longo de uma pesquisa, a fonte oral, ou até mesmo áudio-visual, tornar-se um recurso sem problematização, sem possibilidades de críticas qualitativas, a tarefa perde seu valor e vira gesto sem sentido. Há trabalhos que incluem entrevistas, ou filmagens, sem problematizá-las. Se o fator tempo delimita um aprofundamento conceitual, tão comum nos projetos de pesquisa, que pelo menos se estabeleça os objetivos que serão desempenhados nessa tarefa, seguidos das normas padrão da história oral, sobretudo em seus aspectos técnicos. Antes de tratar a fonte oral na pesquisa, o discente tem que ter consciência da importância da elaboração de um roteiro, reconhecendo sua flexibilidade. Assim como, ter atenção com a transcrição, para não perder conteúdo e perder informações precisas.

É necessário destacar a escolha da fonte a ser utilizada. Não é qualquer pessoa que está habilitada a tratar de um assunto específico. De preferência deve ser um entrevistado que tenha relação com o tema e que reúna condições incontestáveis para a entrevista, como disponibilidade e credibilidade. Nessas circunstâncias, o tipo de entrevista mais recomendável é a entrevista temática. Isso não implica o abandono de um resumo biográfico do entrevistado. É necessário estimular a realização de no mínimo duas entrevistas, de preferência com fontes que tenham posicionamentos distintos em relação a um tema.

Nos programas de história oral são comuns as entrevistas com pessoas com mais idade. Tal regra não impede que se utilizem depoimentos de pessoas com menos idade. Essa medida também vale para um trabalho de dimensões curtas, o fundamental é a credibilidade que a fonte proporciona em sua narrativa.

Outro dado significativo é o procedimento relacionado ao uso público do depoimento. Credenciado pela coordenação do seu curso, com uma declaração comprovando o vínculo institucional, a credibilidade e a confiança do entrevistado são reforçadas. Nessas condições o discente poderá escolher as fontes orais fora do seu ciclo pessoal, como professores do mesmo curso em que atua, e estimula a representação junto a entidades ou grupos que possam contribuir para a realização da pesquisa. Nada impede trabalhar com pessoas de suas relações pessoais. Porém, com critérios definidos.

É importante ter cuidado com a exposição do depoimento de uma pessoa. Daí a necessidade de um documento que autorize o seu uso público, evitando problemas jurídicos e desgastes desnecessários.

Por último, e talvez o principal, uma entrevista - seja filmada ou gravada - deve ser analisada a partir de outras informações que o pesquisador possui. Ela não contém toda a abordagem de um assunto e toda a cientificidade. É apenas uma fonte, quem a torna 
documento passível de análise crítica é o pesquisador, independente do estágio que ele se encontre no seu ofício.

\section{CONCLUSÃO}

A história oral não deve mais ser colocada em dúvida. Sua legitimidade e sua absorção pela teoria da história já são uma realidade incontestável. Nem por isso ela deve ser encarada como a única maneira de produzir um conhecimento histórico recente. É apenas uma metodologia elucidativa, fundamental para a correlação com as fontes oficiais e serve para ampliar o conhecimento de um determinado assunto. É fundamental o seu incentivo nos programas de cursos universitários. Além da sua contribuição científica, é bom lembrar que as fontes orais não são eternas e determinados acontecimentos podem ser esclarecidos com a riqueza de detalhes expostos nas entrevistas realizadas. Atores sociais têm liberdade de escolha e representações individuais, que refletem uma visão coletiva, elucidativas na construção do conhecimento.

A polêmica em torno da subjetividade do entrevistado e do entrevistador, deve ser flexibilizada pelos rigores e regras metodológicas que, há tempos, são objeto de estudo da história oral. Em 1994, na realização do II Encontro Nacional de História Oral, foi fundada no Brasil a Associação Brasileira de História Oral (ABHO); dois anos depois, em 1996, em Gotemburgo, na Suécia, surgiu a International Oral History Association (IOHA), demonstrando que o alcance da história oral na pesquisa não é definitivo e o debate, e suas as reformulações, são constantes. Mas, presume-se que o pesquisador esteja imbuído de um rigor acadêmico e com elementos indispensáveis: como a capacidade de análise crítica, responsabilidade e honestidade no trato com as fontes, sejam elas orais ou escritas.

Aliás, a fonte oral pode ser disponibilizada ao público - quando constar de um programa e arquivo - na forma sonora. Nesse caso a edição é fundamental. Pode ser disponibilizada na forma de transcrição, não diminuindo o rigor da sua produção.

Vimos que a história oral é uma metodologia cada vez mais utilizada pelos historiadores. Entretanto, em nenhum momento a este pode ser atribuído seu privilégio. Há um extenso campo de uso da fonte oral nas demais ciências humanas, que é pouco explorado, com algumas exceções, como na antropologia. O mais importante é o seu uso delimitado por um projeto de pesquisa e com os limites que esse se propõe. Daí em diante é seguir as normas e regras metodológicas sugeridas em extensa literatura que possam tornar a tarefa condizente com o conhecimento científico.

O uso da metodologia inerente à história oral, em trabalhos de cursos de graduação, pode enunciar uma iniciação científica qualificada. Ao invés de legitimar uma prática acadêmica descompromissada.

Por último, de modo sucinto e meramente didático, foi nosso intuito compartilhar uma experiência docente. A partir da constatação da dificuldade discente em produzir seus trabalhos com a qualidade mínima necessária, algumas pontuais sugestões foram realizadas. 
Não é o bastante, mas pode ser um indício de que ciência não se faz com irresponsabilidade e com falácia, mas com compromisso.

\section{REFERÊNCIAS BIBLIOGRÁFICAS}

ALBERTI, Verena. Manual de História Oral. Rio de Janeiro: Editora FGV, 2004.

AMADO, Janaína \& FERREIRA, Marieta de Moraes (coords.). Usos \& abusos da história oral. Rio de Janeiro: Editora da Fundação Getúlio Vargas, 1996.

BURKE, Peter. A escrita da História: novas perspectivas. São Paulo: Ed. UNESP, 1992.

POLLAK, Michael. Memória, esquecimento e silêncio. In Revista Estudos Históricos. Rio de Janeiro, vol. 5, no 10, 1992.

THOMPSON, Paul. A voz do passado. Rio de Janeiro: Paz e Terra, 1992.

\section{Informações bibliográficas:}

Conforme a NBR 6023:2002 da Associação Brasileira de Normas Técnicas (ABNT), este texto científico publicado em periódico eletrônico deve ser citado da seguinte forma:

SILVA JUNIOR, Edson Teixeira. História Oral e as Ciências Humanas. Cadernos UniFOA , Volta Redonda, ano 2, nº. 3, mar. 2007. Disponível em:

$<$ http://www.unifoa.edu.br/pesquisa/caderno/edicao/03/61.pdf> 